\begin{tabular}{|l|c|c|c|c|c|}
\hline & \multicolumn{2}{|c|}{ No eASPECTS Assistance } & \multicolumn{2}{c|}{ Yes eASPECTS Assistance } & \\
\hline & \% Overall Agreement & Kappa (95\%Cl) & \% Overall Agreement & Kappa (95\%Cl) & Significant? \\
\hline M1 & $79.8 \%$ & $0.60(0.50-0.69)$ & $91.6 \%$ & $0.83(0.76-0.90)$ & Yes \\
\hline M2 & $69.0 \%$ & $0.38(0.29-0.47)$ & $83.4 \%$ & $0.67(0.58-0.75)$ & Yes \\
\hline M3 & $76.0 \%$ & $0.52(0.43-0.61)$ & $86.0 \%$ & $0.72(0.63-0.81)$ & Yes \\
\hline M4 & $83.8 \%$ & $0.68(0.60-0.75)$ & $93.8 \%$ & $0.88(0.82-0.93)$ & Yes \\
\hline M5 & $72.0 \%$ & $0.44(0.36-0.52)$ & $83.0 \%$ & $0.66(0.58-0.74)$ & Yes \\
\hline M6 & $87.2 \%$ & $0.74(0.66-0.83)$ & $91.6 \%$ & $0.83(0.76-0.91)$ & No \\
\hline Caudate & $85.5 \%$ & $0.71(0.63-0.79)$ & $89.1 \%$ & $0.78(0.70-0.87)$ & No \\
\hline Lentiform & $71.8 \%$ & $0.44(0.33-0.54)$ & $82.6 \%$ & $0.65(0.56-0.75)$ & Yes \\
\hline Insula & $67.7 \%$ & $0.35(0.27-0.44)$ & $78.7 \%$ & $0.57(0.47-0.67)$ & Yes \\
\hline $\begin{array}{l}\text { Internal } \\
\text { Capsule }\end{array}$ & $81.2 \%$ & $0.62(0.53-0.72)$ & $91.2 \%$ & $0.82(0.76-0.89)$ & Yes \\
\hline
\end{tabular}

\begin{tabular}{|c|c|c|c|}
\hline & \multicolumn{3}{|c|}{ Accuracy } \\
\hline & $\begin{array}{c}\text { All raters overall no } \\
\text { eASPECTS }\end{array}$ & $\begin{array}{c}\text { All raters overall } \\
\text { with eASPECTS }\end{array}$ & eASPECTS \\
\hline M1 & $80.70 \%$ & $87.10 \%$ & $90.00 \%$ \\
\hline M2 & $69.00 \%$ & $83.60 \%$ & $91.70 \%$ \\
\hline M3 & $80.80 \%$ & $87.10 \%$ & $93.30 \%$ \\
\hline M4 & $87.50 \%$ & $93.50 \%$ & $95.00 \%$ \\
\hline M5 & $78.00 \%$ & $86.00 \%$ & $93.30 \%$ \\
\hline M6 & $87.10 \%$ & $91.70 \%$ & $95.00 \%$ \\
\hline C & $80.10 \%$ & $79.00 \%$ & $73.30 \%$ \\
\hline L & $66.60 \%$ & $71.50 \%$ & $71.70 \%$ \\
\hline In & $68.40 \%$ & $79.10 \%$ & $85.00 \%$ \\
\hline IC & $85.10 \%$ & $95.00 \%$ & $100.00 \%$ \\
\hline
\end{tabular}

and 0.62 to 0.82 for the insula. Overall reader accuracy improved with the use of eASPECTS for every region with the exception of the caudate. For example, accuracy improved from $80.7 \%$ to $87.1 \%$ for M1, $69.0 \%$ to $83.6 \%$ for M2 and $85.1 \%$ to $95.0 \%$ for internal capsule. The eASPECTS software had higher accuracy than the overall cohort of readers (with and without eASPECTS assistance) for every region except the caudate.

Conclusions The use of Brainomix eASPECTS software result in significant improvements in the inter-rater agreement and accuracy of ASPECTS score evaluation in a large group of neuroradiologists and neurologists. Interestingly, the eASPECTS software was more predictive of final infarct/ASPECTS than the overall group of readers interpreting the CT scans with and without eASPECTS assistance.

Disclosures W. Brinjikji: None. J. Benson: None. N. Campeau: None. C. Carr: None. P. Cogswell: None. J. Klaas: None. G. Liebo: None. J. Little: None. P. Luetmer: None. S. Messina: None. A. Nagelschneider: None. K. Schwartz: None. C. Wood: None. D. Nasr: None. S. Braksick: None. D. Kallmes: None.

\section{E-157 ARTIFICIAL INTELLIGENCE DETECTION OF CEREBRAL ANEURYSMS USING CT ANGIOGRAPHY - PROOF OF CONCEPT}

${ }^{1} \mathrm{~V}$ Mendes Pereira*, ${ }^{1} \mathrm{~N}$ Cancelliere, ${ }^{2} \mathrm{G}$ Begin, ${ }^{3} \mathrm{Y}$ Donner, ${ }^{3} \mathrm{G}$ Levi, ${ }^{3} \mathrm{E}$ Wasserman, ${ }^{1} \mathrm{~K}$ Lobato Mendes, ${ }^{3} \mathrm{D}$ Golan, ${ }^{1} \mathrm{P}$ Nicholson, ${ }^{4} \mathrm{R}$ Nogueira, ${ }^{1} \mathrm{~T}$ Krings. ${ }^{1}$ Medical Imaging and Neurosurgery, Toronto Western Hospital - University Health Network, Toronto, ON, Canada; ' ${ }^{2}$ iz, Tel Aviv, Israel; ${ }^{3}$ Viz.ai, Tel Aviv, Israel; ${ }^{4}$ Neurology, Grady Medical Center, Atlanta, GA

\subsection{6/neurintsurg-2020-SNIS. 189}

Introduction Brain Aneurysms (BAs) are a prevalent vascular disease that may cause a life-threatening intracranial hemorrhage. They can often be missed in CTA and MRAs because the diagnosis requires a very methodological approach.
Machine learning algorithms have been used to detect large vessel occlusion and other vascular brain conditions. We developed an algorithm using deep neural network to detect and assist BAs.

Methods We developed an algorithm using 3D convolutional neural network modeled as U-net to detect BAs. We used consecutive positive and negative CTAs in two institutions from 2015-2017. The data was annotated by experienced researchers and checked by an experience neuroradiologist. The algorithm construction used initially 179 CTA datasets containing 230 BAs as a training set. After an initial assessment and algorithm optimization, we use 528 CTAs containing 674 BAs and 2400 normal scans as validation set. We aim to perform a blind test on the algorithm to assess its accuracy on detection of BAs using a test set of 300 positive CTAs with BAs independent of the rupture status and larger than $5 \mathrm{~mm}$ and 900 negative scans as controls consecutively selected matched by age and sex. We used ROC curves and Pearson correlation tests to assess the algorithm.

Results We are submitting preliminary results of a blind test of 50 positive CTAs and 150 controls. The algorithm achieved a sensitivity of $92 \%$ and a specificity of $94 \%$ (AUC 0.983). At the time of the conference, we aim to present the complete analysis and subgroup analysis per location, size and rupture status.

Conclusion The Viz. ai aneurysm algorithm was able to accurately detect the majority of brain aneurysms from our blind test dataset. More importantly, it was also able to report consistently the negative scans. Further training should improve even more accuracy particularly on small aneurysm sizes.

Disclosures V. Mendes Pereira: 2; C; iz.ai, Medtronic, Stryker, Balt, Cerenovous, Phenox. N. Cancelliere: None. G. Begin: 5; C; employee of Viz.ai. Y. Donner: 5; C; employee of Viz.ai. G. Levi: 5; C; Emploee of viz.ai. E. Wasserman: 5; C; Emploee of viz.aiployee of Viz.ai. K. Lobato Mendes: None. D. Golan: 5; C; Emploee of viz.aiploee of viz.aiployee of Viz. ai. P. Nicholson: None. R. Nogueira: 2; C; viz.ai. T. Krings: None. 